\title{
Air Quality and Health Impacts of Future Ethanol Production and Use in São Paulo State, Brazil
}

\author{
Noah Scovronick ${ }^{1,2, *}$, Daniela França ${ }^{3}$, Marcelo Alonso ${ }^{4}$, Claudia Almeida ${ }^{5}$, Karla Longo ${ }^{5,+}$, \\ Saulo Freitas ${ }^{5, \dagger}$, Bernardo Rudorff ${ }^{6}$ and Paul Wilkinson ${ }^{2}$ \\ 1 Woodrow Wilson School and Climate Futures Initiative, Princeton University, Princeton, NJ 08544, USA \\ 2 Department of Social and Environmental Health Research, London School of Hygiene and \\ Tropical Medicine, London WC1E 7HT, UK; Paul.Wilkinson@1shtm.ac.uk \\ 3 Instituto de Geociências, Universidade Federal do Rio de Janeiro, Rio de Janeiro, RJ 21941-916, Brazil; \\ daniela.franca@igeo.ufrj.br \\ 4 Faculdade de Meteorologia, Universidade Federal de Pelotas (Federal University of Pelotas), \\ Capão de Leão, RS 35903-087, Brazil; marcelo.alonso@ufpel.edu.br \\ 5 Instituto Nacional de Pesquisas Espaciais (National Institute For Space Research), \\ São José dos Campos, SP 12227-010, Brazil; almeida@dsr.inpe.br (C.A.); karla.longo@cptec.inpe.br (K.L.); \\ saulo.freitas@cptec.inpe.br (S.F.) \\ 6 Agrosatélite Geotecnologia Aplicada Ltda., Florianópolis, SC 88032-005, Brazil; \\ bernardo@agrosatelite.com.br \\ * Correspondence: Noah.Scovronick@princeton.edu; Tel.: +1-609-258-9897 \\ + Current address: Universities Space Research Association/Goddard Earth Sciences Technology and \\ Research (USRA/GESTAR) and Global Modeling and Assimilation Office (GMAO), NASA/Goddard Space \\ Flight Center, Greenbelt, MD 20771, USA; karla.longo@nasa.gov (K.L.); saulo.r.freitas@nasa.gov (S.F.).
}

Academic Editor: Nelson Gouveia

Received: 10 April 2016; Accepted: 29 June 2016; Published: 11 July 2016

\begin{abstract}
It is often argued that liquid biofuels are cleaner than fossil fuels, and therefore better for human health, however, the evidence on this issue is still unclear. Brazil's high uptake of ethanol and role as a major producer makes it the most appropriate case study to assess the merits of different biofuel policies. Accordingly, we modeled the impact on air quality and health of two future fuel scenarios in São Paulo State: a business-as-usual scenario where ethanol production and use proceeds according to government predictions and a counterfactual scenario where ethanol is frozen at 2010 levels and future transport fuel demand is met with gasoline. The population-weighted exposure to fine particulate matter $\left(\mathrm{PM}_{2.5}\right)$ and ozone was $3.0 \mu \mathrm{g} / \mathrm{m}^{3}$ and $0.3 \mathrm{ppb}$ lower, respectively, in 2020 in the scenario emphasizing gasoline compared with the business-as-usual (ethanol) scenario. The lower exposure to both pollutants in the gasoline scenario would result in the population living 1100 additional life-years in the first year, and if sustained, would increase to 40,000 life-years in year 20 and continue to rise. Without additional measures to limit emissions, increasing the use of ethanol in Brazil could lead to higher air pollution-related population health burdens when compared to policy that prioritizes gasoline.
\end{abstract}

Keywords: biofuel; ethanol; air quality; emissions; pollution; health; cardiovascular; transport

\section{Introduction}

As one of the few alternatives to fossil fuels in the transport sector, liquid biofuels have received increased attention for their potential to help mitigate climate change, improve energy security, and revitalize agricultural economies. Accordingly, use of these plant-based fuels has increased dramatically in recent years; from 2007 to 2014, global ethanol production nearly doubled, and strong growth is expected to continue [1-3]. 
It is also often argued that liquid biofuels are cleaner than fossil fuels, and by implication, better for human health (e.g., [4,5]). The literature on this issue however, is not conclusive. Results from emission experiments show marked sensitivity to the vehicle studied (age and type), operating conditions, blend ratio, and possibly to the biofuel's feedstock crop [6-10]. There may also be trade-offs between health-relevant pollutants, as some biofuel blends have shown a tendency towards reduced particulate matter (PM) but increased ozone precursors when compared to their fossil fuel counterparts [6-9]. This variability has led some experts to expect relatively large air quality impacts from moving towards ethanol while others argue that the impacts are likely to be more modest or not meaningful $[4,5,7,8,10,11]$.

Whereas most countries began producing biofuels on an industrial scale relatively recently, the Brazilian biofuel program was initiated in response to the oil crisis of 1973. As a result of this head start, and vast agricultural resources, Brazil is the only country in the world resembling a biofuel (ethanol) society; nearly all new passenger cars in Brazil are "flex-fuel", capable of using up to 100\% ethanol or gasoline, and ethanol meets around a third of the country's gasoline needs in the transport sector [12-14]. Brazil also produces about a quarter of the world's ethanol, made primarily from sugarcane, with production in 2014/2015 estimated at 28.4 billion liters [1,15].

The Brazilian experience therefore offers the most appropriate case study to assess potential costs and benefits resulting from different biofuel policies. Nevertheless, few studies have explored the air quality and health impacts associated with ethanol production and use in Brazil, despite strong indications of biofuel-related disease burdens; epidemiological studies have linked the pre-harvest burning of sugarcane straw with adverse respiratory outcomes in industry workers and the general population [16-19], while many Brazilian cities (including São Paulo) have pollution levels far exceeding World Health Organization (WHO) air quality guidelines [20,21].

In this paper, we compare the impacts on air quality and health of two future transport fuel scenarios in São Paulo State, Brazil: one where ethanol production and use proceeds according to government predictions and one that instead emphasizes gasoline. São Paulo State (Figure 1) is Brazil's most populous state ( 41.5 million inhabitants), includes its largest metropolitan area (São Paulo), and is responsible for half of the country's ethanol production [15].

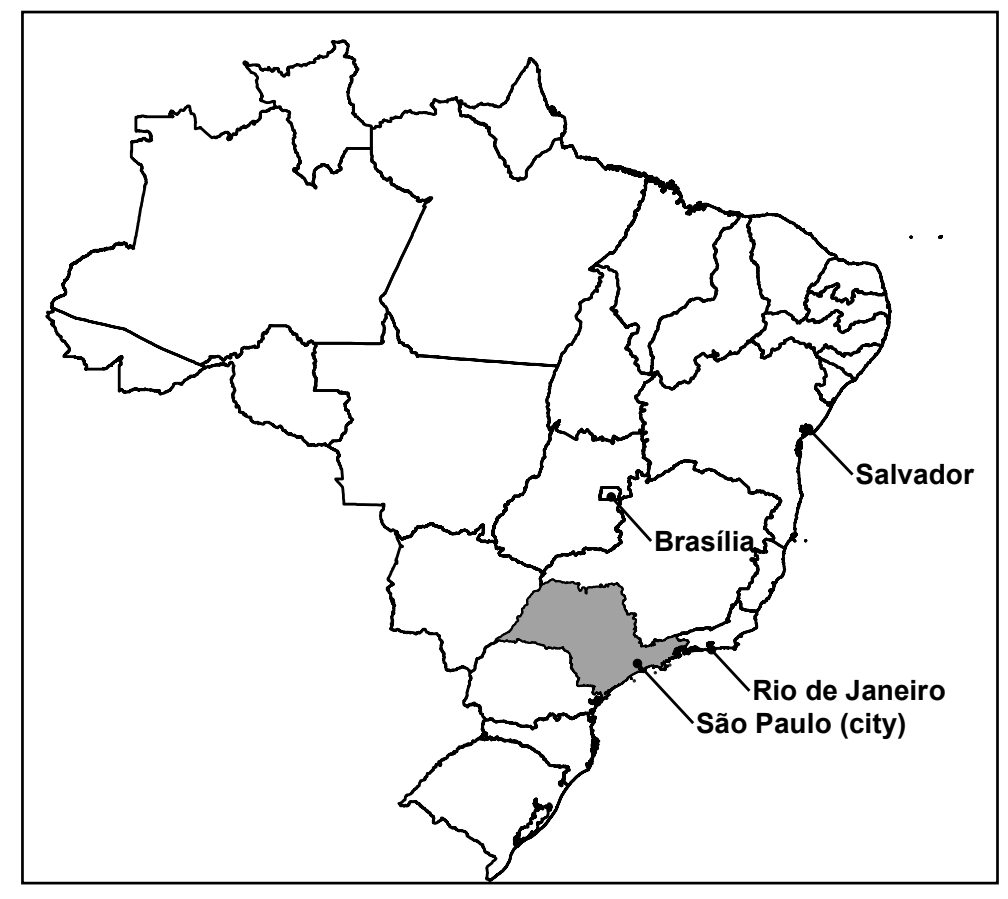

Figure 1. Location of São Paulo State (shaded). 


\section{Materials and Methods}

We estimated air quality and associated mortality burdens from exposure to $\mathrm{PM}_{2.5}$ and ozone for the 12-month period from October 2019 to September 2020 assuming two different scenarios of future ethanol production and use. October 2019 to September 2020 was chosen instead of a calendar year in order to include one full and continuous warm (October-March) and cold (April-September) season. In both scenarios, and in line with 2007 government projections [22], transport fuel demand in Brazil in 2020 is $\sim 40 \%$ higher than 2010 levels, with a total demand of 110,000 MW. Vehicle fleets were also the same in both scenarios, with all new cars assumed to be flex-fuel (see Section 2.1.2 below for details). Where the two scenarios differed was in how the transport energy demand was met, as follows:

Scenario 1: A business-as-usual scenario where ethanol production and use proceed through 2020 according to government projections. In this scenario, fossil fuel demand increases by $46 \%$ $(12,700 \mathrm{MW})$ and ethanol by $42 \%$ (3800 MW). This scenario is hereafter referred to as the "Ethanol Expansion" scenario.

Scenario 2: A counterfactual "Fossil Fuel" scenario where all additional non-diesel transport energy demand (16,500 MW) after 2010 is met with fossil fuels (gasoline). Ethanol production is therefore frozen at 2010 levels and the only ethanol consumed is either as an additive to gasoline (Brazilian law mandates that gasoline contains $~ 22 \%$ anhydrous ethanol) or in the small number of ethanol-only vehicles still in circulation in 2019/2020 (see Section 2.1.2 below for details). The additional fossil fuel production is assumed to occur outside of the study area.

\subsection{Emissions}

Differences in air quality between the scenarios result from differing levels of two types of emissions: from pre-harvest burning of sugarcane straw and from emissions during end-use of transport fuel.

\subsubsection{Emissions from Sugarcane Straw Burning}

In certain areas of Brazil, sugarcane fields are burned prior to harvest in order to enable easier access to the cane. The burning season runs between about April and December, a period that approximately corresponds to the cold season. Burning is being phased out in favor of mechanized harvesting, but is expected at least to some degree over the coming years.

To model the associated emissions, we used spatially explicit projections of future sugarcane cultivation and associated burning in São Paulo State (the projections were generated by Dr. Claudia Almeida of Brazil's National Institute for Space Research (INPE) for a study titled "The spatial scenarios of sugarcane expansion and harvesting practices". The projections were based on forecasts from the Brazilian Sugarcane Industry Association (UNICA) and data from the CANASAT project coordinated by Dr. Bernardo Rudorff and processed in conjunction with Dr. Daniel Alves Aguiar and Moises Pereira Galvao Salgado (all at INPE). The work is being prepared for publication). The estimates indicate that the Ethanol Expansion scenario would result in 1,079,207 additional hectares of sugarcane harvested in 2020 compared to the Fossil Fuel scenario and an extra 159,077 hectares burnt (Supplementary Section S1). However, due to the expected increase in coverage of mechanized harvesting, the burnt area declines substantially over time in both scenarios and in 2020 comprises only $5.1 \%$ and $3.5 \%$ of the total harvest area in the two scenarios, respectively (Supplementary Section S1). Emission factors for sugarcane straw burning are from França et al. [23] and Yokelson et al. [24].

\subsubsection{Vehicle Emissions}

The vehicle fleet was separated by fuel type and into four vehicle categories: cars, light-duty commercial vehicles, trucks and buses [25]. Circulating vehicle numbers in 2019/2020 were based on licensing data through 2010, a published scrapping rate, and projections of future vehicle sales [25-27]. In line with recent trends, all new cars are assumed to be flex-fuel [28] and therefore differences in 
vehicle emissions result only from the type of fuel consumed; the vehicle fleet and the total transport energy demand is the same in both scenarios (Supplementary Section S2).

Emission factors through 2011 are from data published by São Paulo State's Environmental agency (CETESB) [29] and we assumed that new vehicles from 2012 onwards had the 2011 emissions factors (Supplementary Section S3). Time-series of projected vehicle emissions (carbon monoxide [CO], oxides of nitrogen (NOx) and volatile organic compounds (VOCs)) through 2020 can be found in Supplementary Section S4. As CETESB does not report primary PM emissions from all vehicle types, we used $\mathrm{CO}$ as a proxy and then employed a standard empirical relation between $\mathrm{CO}$ and $\mathrm{PM}_{2.5}$ to include primary $\mathrm{PM}_{2.5}$ emissions in the air quality model [30].

\subsubsection{Other Emissions}

The only other emission source that was projected forward was from deforestation (slash-and-burn agriculture) unrelated to sugarcane expansion. The future estimates were available from a prior World Bank study [31] and were assumed to be the same in both scenarios. Emissions from other anthropogenic sources and biogenic sources did not change through time in either scenario and were based on emission inventories [32-35].

\subsection{Air Quality Modeling}

Air quality was modeled with the Coupled Chemistry Aerosol-Tracer Transport model to the Brazilian developments on the Regional Atmospheric Modeling System (CCATT-BRAMS), an on-line regional chemical transport model developed for integrated air quality and weather forecasting and research. It simulates gaseous/aqueous chemistry, transport, dispersion, chemical transformations and removal processes associated with gases and aerosols in the atmosphere and has been described in detail elsewhere $[34,36]$. Briefly, the model integrates emissions data with meteorological factors and initial and boundary conditions to produce air quality estimates for the modeling domain-in this case São Paulo State. The modeling was conducted at a resolution of $10 \mathrm{~km} \times 10 \mathrm{~km}$ and air quality was then determined for every one of the 645 municipal polygons based on the concentration at the location of the municipal seat (municipal polygons were rarely situated entirely within a single grid square). We report annual concentrations and also separated by season (warm and cold).

\subsection{Health Impact Calculations}

We estimated the difference in health that would result from the difference in air quality between the two scenarios using life table methods based on the IOMLIFET model $[37,38]$, populated with age- and sex-specific data for São Paulo State in 2010, as reported by the Brazilian government (and described in Supplementary Section S5) [39-41]. Life tables model survival patterns over time, providing estimates of deaths, life-years (LY) lived and life expectancy in each year and for each age-sex group. We allowed a time-horizon (follow-up period) of 106 years, but emphasize impacts over the first 20 years, as the longer 106 year time period would entail strong non-biofuel related influences on health patterns. We assumed that the annual number of births remains constant and that underlying death rates did not change over time.

To model the difference in health between the scenarios, we assumed that age-specific death rates (hazards) in the Ethanol Expansion (business-as-usual) scenario remained constant at 2010 values. Deaths under the counterfactual fossil fuel scenario were computed by applying relative risks to age-specific death rates corresponding to the difference in air pollution concentrations for $\mathrm{PM}_{2.5}$ and ozone between the Ethanol Expansion and the counterfactual Fossil Fuel scenario.

Air pollution has been associated with mortality from a wide range of causes [42,43]. We included impacts from three non-overlapping pollutant-outcome pairs, as guided by recent WHO technical reports [43,44], using concentration-response functions from cohort studies of long-term exposure in adults. The first pollutant-outcome pair is cardiovascular mortality from $\mathrm{PM}_{2.5}$ exposure and was based on coefficients reported in the meta-analysis by Hoek et al. [45], but updated by Forestiere et al. for the WHO [44]. The meta-analysis includes studies from North America and elsewhere. 
The second is $\mathrm{PM}_{2.5}$-related mortality from lung cancer quantified with coefficients from Hamra et al. [46]. And the third is ozone-related respiratory mortality from Jerrett et al., [47], which is the only ozone-related outcome that remained significant in two-pollutant models. The concentration-response functions are displayed in Table 1. For both ozone and $\mathrm{PM}_{2.5}$ we used (log)linear models without a threshold and did not differentiate between specific components of PM. In line with the study population in the cohort studies, hazards were only applied to adults (30+). As sensitivity analyses, we ran the models using the lower and upper confidence interval of the concentration-response functions (in addition to the central estimates) and with concentration-response functions for all-cause mortality (Table 1).

Table 1. Concentration-response functions used in estimating health impact.

\begin{tabular}{|c|c|c|c|}
\hline Study & Exposure & Mortality Cause * & Percent Change (95\% CI) \\
\hline \multicolumn{4}{|c|}{ Main results } \\
\hline $\begin{array}{l}\text { Hoek et al. (2013) [45] and } \\
\text { Forestiere et al. (2014) [44] }\end{array}$ & $10 \mu \mathrm{g} / \mathrm{m}^{3} \mathrm{PM}_{2.5}$ annual average & Cardiovascular & $10.0(5.0,15.0)$ \\
\hline Hamra et al. (2014) [46] & $10 \mu \mathrm{g} / \mathrm{m}^{3} \mathrm{PM}_{2.5}$ annual average & Lung cancer & $9.0(4.0,14.0)$ \\
\hline Jerrett et al. (2009) [47] & $10 \mathrm{ppb} \mathrm{O}_{3}$ warm-season average of $1 \mathrm{~h} \max$ & Respiratory $^{\dagger}$ & $4.0(1.3,6.7)$ \\
\hline
\end{tabular}

* ICD-10 codes: Cardiovascular $=$ I00-I99, Respiratory $=$ J00-J99, Lung cancer $=$ C33-C34; ${ }^{+}$Two-pollutant model (controlled for $\mathrm{PM}_{2.5}$ ); $\mathrm{CI}=$ confidence interval.

As we did not model air quality for all years prior to $2019 / 2020$, our modeling approach assumes that the change in air quality occurs instantaneously, as do the corresponding health impacts (no onset lags were included). Therefore, the results should be interpreted as the change in population health that would result from a sustained difference in exposure to ozone and particulate air pollution.

\section{Results}

Most of São Paulo State's 645 municipalities had annual average modeled $\mathrm{PM}_{2.5}$ concentrations between $17-25 \mu \mathrm{g} / \mathrm{m}^{3}$, although a small number had much higher concentrations (Figure 2, Supplementary Section S6). The highest concentrations were generally located in urban areas, particularly around São Paulo city, and are in large part attributable to emissions from semi-heavy and heavy-duty diesel trucks, which have been markedly increasing in numbers of late as reflected in both scenarios $[29,48]$. Higher $\mathrm{PM}_{2.5}$ concentrations in the metropolitan region of São Paulo are consistent with recent reporting $[29,48,49]$.

In $60 \%$ of municipalities, the annual average concentration of $\mathrm{PM}_{2.5}$ was higher in the Ethanol Expansion compared to the Fossil Fuel scenario, but there was marked seasonal variability: $100 \%$ of municipalities were higher in summer in the Ethanol Expansion scenario but only 19\% in winter (Figure 3). In the vast majority of municipalities and in all time periods, the difference between the scenarios was $\leqslant 1 \mu \mathrm{g} / \mathrm{m}^{3}$ (Figure 3). However, the population-weighted annual average $\mathrm{PM}_{2.5}$ concentration in the Ethanol Expansion scenario was $3.0 \mu \mathrm{g} / \mathrm{m}^{3}$ higher than the Fossil Fuel scenario, attributable to the relatively large differences in some highly populated municipalities, including São Paulo municipality which contains $27 \%$ of the state's population (Figure 3, Supplementary Section S7). 

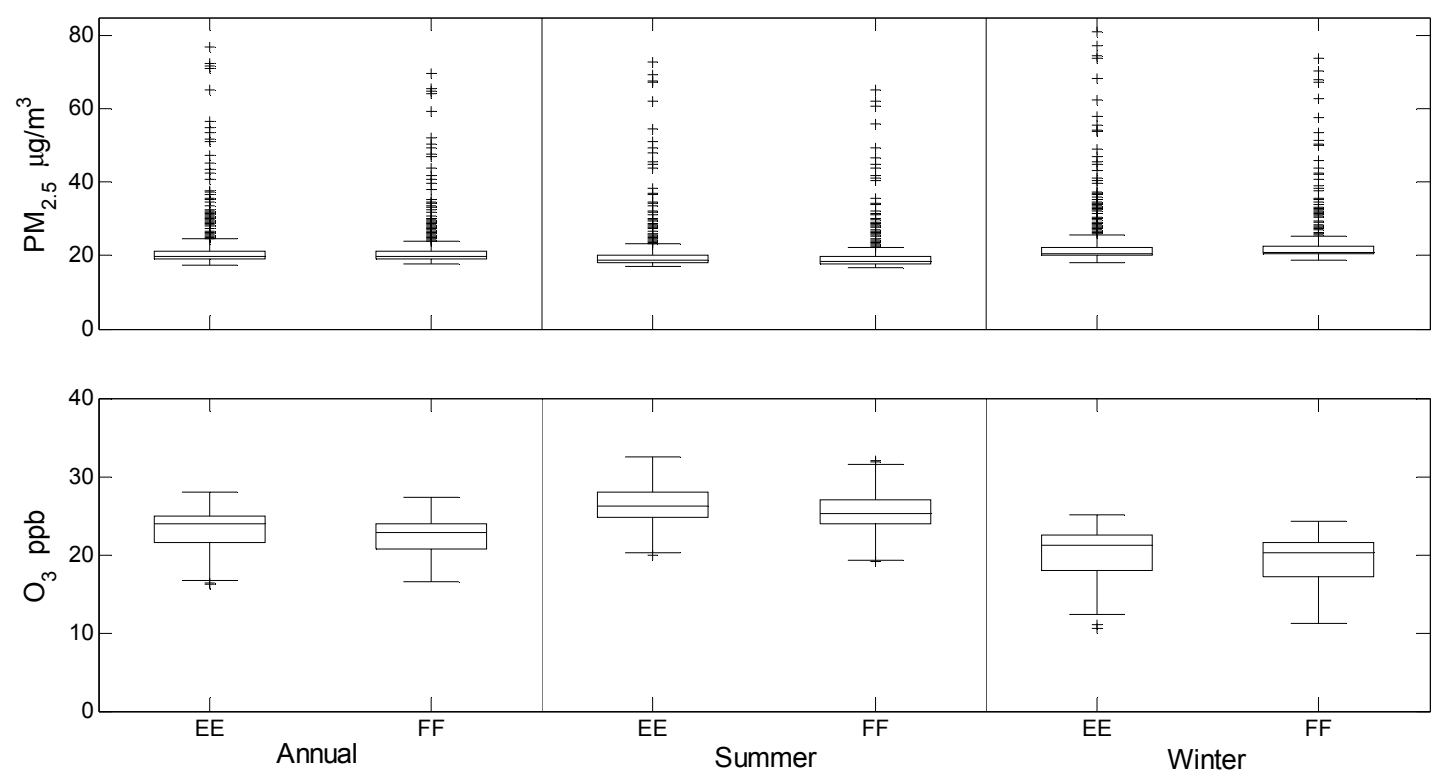

Figure 2. Boxplots summarizing annual, warm and cold season concentrations of fine particulate matter $\left(\mathrm{PM}_{2.5}\right)$ and ozone $\left(\mathrm{O}_{3}\right)$ in the 645 municipalities of São Paulo State in the Ethanol Expansion (EE) and Fossil Fuel (FF) scenarios.
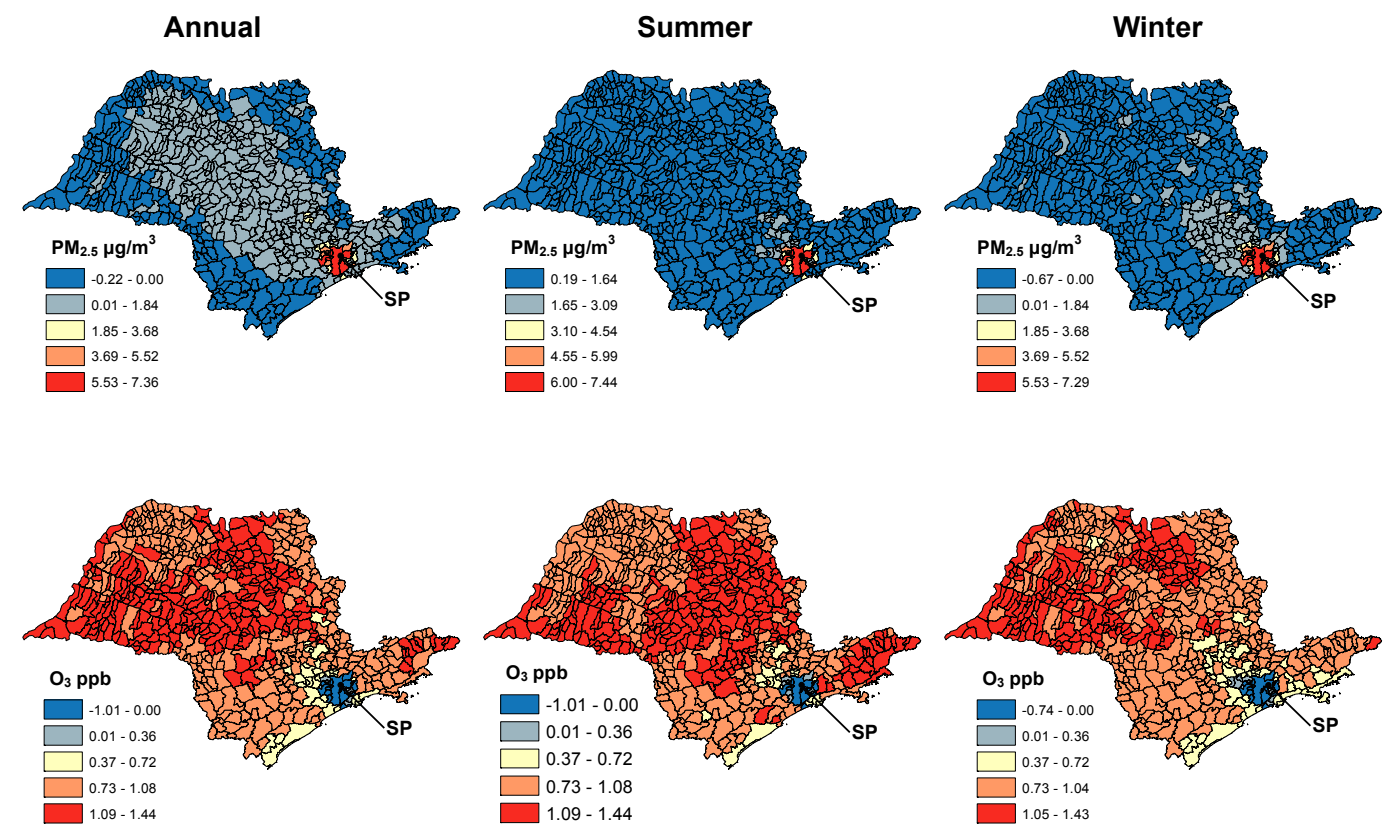

Figure 3. Difference in the concentration of fine particulate matter $\left(\mathrm{PM}_{2.5}\right)$ (average) and ozone $\left(\mathrm{O}_{3}\right)$ (average of $1 \mathrm{~h}$ maximums) in each of the 645 municipalities of São Paulo State. Positive values indicate higher concentrations in the Ethanol Expansion scenario.

Ozone concentrations in both scenarios were mainly between 15-30 ppb (Figure 2, Supplementary Section S6). As with $\mathrm{PM}_{2.5}$, ozone concentrations were generally higher in the Ethanol Expansion scenario (Figures 2 and 3), with $\sim 97 \%$ of municipalities showing this result in all three time periods. However, of the few municipalities with higher ozone in the Fossil Fuel scenario, many were high-population areas including São Paulo municipality (Figure 3, Supplementary Section S7). 
The population-weighted warm season ozone concentration in the Ethanol Expansion scenario was $0.29 \mathrm{ppb}$ higher than in the Fossil Fuel scenario.

The lower exposure to both $\mathrm{PM}_{2.5}$ and ozone in the Fossil Fuel scenario resulted in more life-years lived by the population of São Paulo State as a whole. The increase was 1100 life-years in the first year, and if sustained, would rise almost linearly to 40,000 in year 20 (Table 2). Gains occurred in all pollutant-outcome pairs, although the vast majority $(\sim 90 \%)$ was from $\mathrm{PM}_{2.5}$-related cardiovascular disease (Table 2, Supplementary Section S8).

Figure 4 projects impacts over the whole 106-year follow-up period, assuming that the differences in air quality are sustained throughout. Benefits continue to accrue to a maximum impact of $\sim 80,000$ life-years per year is gained after about 55 years of follow-up. Impacts then decrease slightly to $\sim 60,000$ per year and level off. For context, the birth cohort experiencing these reduced risks would have an increased life expectancy of approximately four weeks.

Table 2. Additional life-years lived per year by the population in the Fossil Fuel compared to the Ethanol Expansion scenario at three time points (Year 1, Year 10 and Year 20).

\begin{tabular}{|c|c|c|c|}
\hline Follow-up & Cause & $\begin{array}{c}\text { Additional Life-Years Lived in } \\
\text { the Fossil Fuel Scenario }{ }^{+}\end{array}$ & $\begin{array}{c}\text { Additional Life-Years Per } \\
\text { Million Population }(30+)^{+, *}\end{array}$ \\
\hline \multirow[t]{4}{*}{ Year 1} & Total & $1140(580-1670)$ & $50(30-80)$ \\
\hline & Cardiovascular $\left(\mathrm{PM}_{2.5}\right)$ & $1060(550-1540)$ & $50(30-70)$ \\
\hline & Lung cancer $\left(P M_{25}\right)$ & $70(30-100)$ & $3(1-5)$ \\
\hline & Respiratory $\left(\mathrm{O}_{3}\right)$ & $20(10-30)$ & $1(0-1)$ \\
\hline \multirow[t]{4}{*}{ Year 10} & Total & $20,620(10,490-30,190)$ & $950(480-1390)$ \\
\hline & Cardiovascular $\left(\mathrm{PM}_{2.5}\right)$ & $19,060(9820-27,790)$ & $880(450-1280)$ \\
\hline & Lung cancer $\left(P M_{2.5}\right)$ & $1260(580-1910)$ & $60(30-90)$ \\
\hline & Respiratory $\left(\mathrm{O}_{3}\right)$ & $290(100-480)$ & $10(0-20)$ \\
\hline \multirow[t]{4}{*}{ Year 20} & Total & $39,800(20,240-58,310)$ & $1840(930-2690)$ \\
\hline & Cardiovascular $\left(\mathrm{PM}_{2.5}\right)$ & $36,750(18,910-53,610)$ & $1700(870-2470)$ \\
\hline & Lung cancer $\left(P M_{2.5}\right)$ & $2490(1140-3760)$ & $120(50-170)$ \\
\hline & Respiratory $\left(\mathrm{O}_{3}\right)$ & $550(180-900)$ & $40(30-50)$ \\
\hline
\end{tabular}

${ }^{\dagger}$ Rounded; * Denominator is the baseline population $30+$ in the specified year.

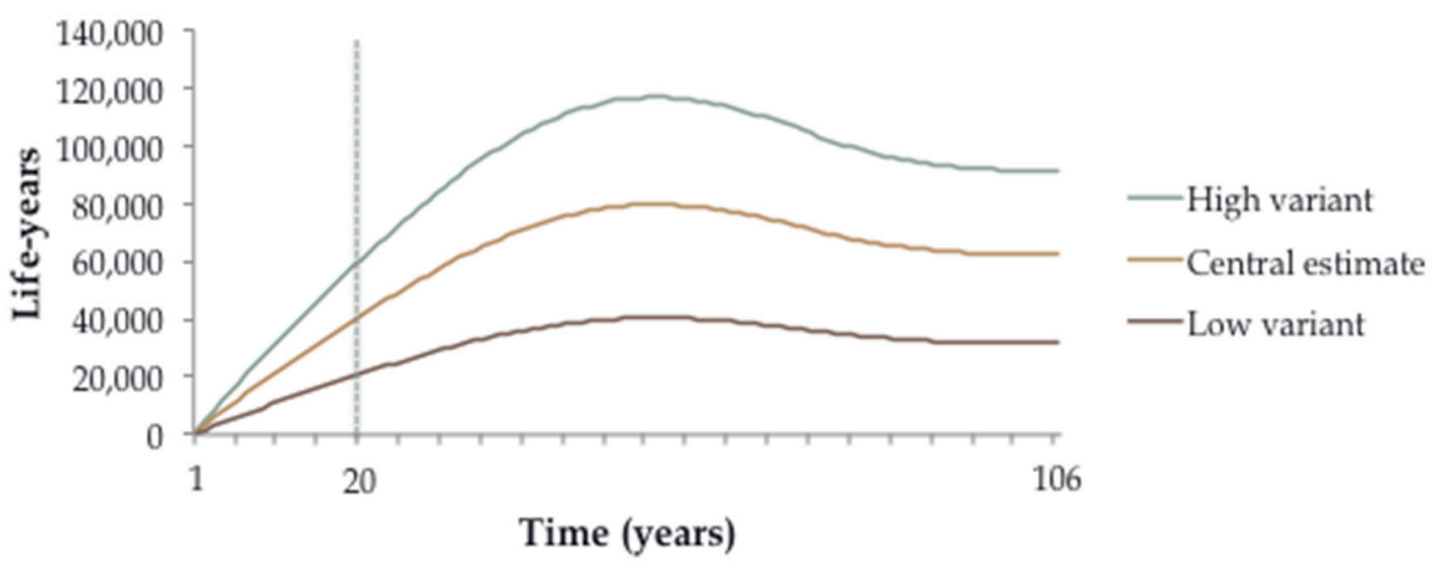

Figure 4. Additional total life-years lived by year in the Fossil Fuel compared to the Ethanol scenario. Low and High variant refers to results estimated using the 5th and 95th confidence intervals in the concentration-response functions, respectively.

The health impact using concentration-response functions estimated for all-cause mortality is about twice the total of the three specific causes (Supplementary Section S9). 


\section{Discussion}

This study suggests that a transport policy promoting ethanol over gasoline would result in more particulate air pollution and higher levels of tropospheric ozone in São Paulo State. As São Paulo State is one of the largest ethanol producing and consuming regions in the world, the results indicate that other countries considering an increase in their use of ethanol should carefully weigh the assumed benefits against potential costs, which we find may include inferior air quality.

Given the estimated difference in pollution (population-weighted differences of $3.0 \mu \mathrm{g} / \mathrm{m}^{3}$ of $\mathrm{PM}_{2.5}$ and $0.3 \mathrm{ppb}$ ozone), in the Fossil Fuel scenario the State's population would live about 1100 additional life-years (50 per million adult population) after one year, and if sustained, this figure would rise to 40,000 life-years (1800 per million adult population) in year 20, all else equal.

Most of the health benefit was associated with exposure to particulate matter and most was from reduced cardiovascular disease. Unsurprisingly, differences were greatest in the high population areas, which are also where most fuel is consumed. The analyses of all-cause mortality suggest that the estimated differences between the scenarios could be conservative, although all-cause mortality is less reliable when applied outside of the population from which the concentration-response functions originated [43]. Had we included potential $\mathrm{PM}_{2.5}$ impacts on respiratory diseases in particular, which are often reported in cohort studies, the cause-specific differences between scenarios would have been substantially more pronounced and closer to the estimates based on all-cause mortality; we did not include them because pooled risk coefficients in recent meta-analyses were not (quite) significant at the $5 \%$ level [43-45].

It is difficult to compare our results with existing studies, as there is substantial variability with respect to the scenarios analyzed, pollutants assessed and the study area, amongst other factors [9]. For example, in a national study of the USA, health costs from corn-based ethanol were higher than gasoline, mainly due to emissions during production, but second-generation ethanol had lower costs [50]. Another study from the USA, which looked specifically at ozone, found that small increases in mortality were likely if vehicles used E85 compared to gasoline [51]. In terms of Brazilian-specific evidence, one study found that adding ethanol to diesel in bus and truck fleet in São Paulo would improve health, but it did not compare gasoline and ethanol or include lighter duty vehicles [52]. More recent research that used highly spatially and temporally resolved observations of road traffic, meteorology and air pollution, together with a consumer demand model found that increased gasoline use in flex-fuel vehicles caused a decline in urban ozone in São Paulo (and an increase in NO and CO), which contrasts with our findings [53]. They did not report results outside of the metropolitan area.

It is important to note that we explored only two of many possible future fuel scenarios-a business-as-usual scenario based on government projections (the "Ethanol Expansion" scenario) and a counterfactual Fossil Fuel scenario. Although the Ethanol Expansion scenario seems the more likely of the two, an important feature of the work is that the Fossil Fuel scenario is also plausible. Brazil's diverse energy matrix and newly discovered oil reserves, combined with increasing international demand for ethanol, allows it unusual flexibility in designing its domestic energy strategy. Additionally, events from a few years ago demonstrated that ethanol consumption in the country is responsive to factors such as domestic oil prices, which were largely blamed for the reduced domestic ethanol consumption in 2011 and 2012 as compared to previous years (it recovered in 2013 and 2014) [15,54]. Nevertheless, updated Brazilian energy demand projections do not show large differences through 2020 compared to the 2007 report on which this study is based [55].

In addition to the scenario design, the results presented above should be interpreted in light of the assumptions and limitations in the modeling approach, some of which were explored in sensitivity analyses. We quantified expected mortality burdens from multiple causes of death and used concentration-response functions from cohort studies that were mainly conducted in North America and Europe. However, it is not yet clear if those functions are entirely appropriate to the Brazilian population. To account for some of the uncertainty in these parameters, we calculated results using the high and low confidence intervals of the different effect sizes, in addition to the central estimate. 
The life-years gained using the high variant was approximately three times higher than the low variant, though still not as high as the central estimate when quantifying effects on all-cause mortality, again partly attributable to our exclusion of respiratory causes.

There are a few specific questions about the ozone-mortality association that also require special mention. The first is whether there is a threshold below which mortality does not occur, an issue that is not yet resolved [43]. The municipalities in the study area had ozone concentrations lower than some suggested thresholds for long-term exposure, normally $\sim 35 \mathrm{ppb}[43,56]$. Therefore, if a threshold for long-term exposure does exist, it is possible that transport fuel choice would not affect ozone-related mortality under these conditions or would affect burdens differently. However, ozone-related effects comprised only a small fraction of the total health impact and did not have a substantive influence on the difference in health impact between the scenarios.

Additionally, there is not much evidence to confirm whether focusing only on summer ozone - normally the case in existing cohort studies [43,47,57]—is appropriate in tropical countries. However, as ozone concentrations were fairly similar in the warm and cold seasons, as were the differences in ozone between the scenarios, results would not be strongly affected by using different seasonal assumptions.

Unlike for the exposure-response parameters, we were not able to test the sensitivity of the air quality estimates to different model parameterizations. This was due to the high computational demands of the CCATT-BRAMS air quality model, which precluded running multiple simulations for each scenario. Three parameters in particular are notable in terms of their potential impact on model results.

The first is the composition of the vehicle fleet, which we assumed was the same in both scenarios. Although it seems almost certain that flex-fuel vehicles will continue to dominate new vehicle sales in Brazil, it is of course not guaranteed, and emission factors do differ depending on whether a vehicle is flex-fuel or conventional gasoline. In 2011, gasoline-only passenger vehicles had lower emissions when compared to flex vehicles using either ethanol or gasoline (see Supplementary Section S3). Light duty commercial vehicles had lower emissions than flex-vehicles driven with ethanol, but flex-gasoline is better in some respects (Supplementary Section S3).

Second, the assumption that all new vehicles have 2011 emissions factors-which was the most recent year available at the time of modeling-does not account for potential changes in vehicle technologies. Although we used emission factors published by São Paulo State's environmental agency (CETESB), a widely used data source, average vehicle emissions change over time and there is no reason to expect that this would not continue. Nevertheless, more recently published estimates for São Paulo State indicate that new flex-fuel vehicles continue to produce higher emissions of most reported pollutants when using ethanol compared to gasoline (an important exception being NOx in 2013 and 2014, though differences were $\leqslant 0.003 \mathrm{~g} / \mathrm{km}$ ) [48,58]. Additionally, the newer data shows that emissions per mile have continued to fall in general, suggesting the absolute levels of emissions estimated here represent an upper limit.

The third is the uncertainty inherent in the projections of future sugarcane burning. The projections we used assume substantial reductions in burning over the coming years. While some will view this assumption as optimistic, many in the industry predict that burning will stop altogether before 2020 [59]. If burning ceased entirely, it would reduce the difference in air quality between the scenarios. However, considering that burning levels were already low in our scenarios and that the meaningful air quality differences occurred mainly in urban areas away from the sugarcane growing regions, it seems unlikely that changes in the burning projections would have a major impact on the study's conclusions.

Other important limitations in our modeling include the fact that health impacts were estimated for 2019/2020 based on the current (2010) population. Although the population in 2019/2020 will not be substantially different, there will be some changes in terms of its size, age-sex structure and health profile, amongst other factors. Additionally, we made some simplifications about the timing of the air quality and health impacts, which are not entirely realistic. The modeling approach effectively assumes 
that air quality changes estimated for 2019/2020 would occur suddenly, rather than evolving over time. Similarly, we did not differentiate between health effects that would occur more immediately (e.g., some cardiovascular diseases) and those with longer induction periods (e.g., lung cancer). Therefore, the results presented above represent the health impact that would be expected to arise over the long term if the differences in air quality were sustained, all else equal.

And finally, we only looked at mortality burdens associated with air pollution-and only from ozone and $\mathrm{PM}_{2.5}$-when other pathways to health would also be affected by the different fuel scenarios. Examples include possible impacts on occupational health or road traffic injuries if fuel availability (or price) were to affect driving patterns. Much has also been made of the effect of liquid biofuels on food prices, though sugarcane ethanol does not influence food prices to the same extent as some other biofuel feedstock crops [60].

Similarly, our study focused only on mortality, as mortality normally dominates air pollution—related disease burdens [43]. Adding morbidity estimates would be a worthwhile extension of this work considering there is strong evidence of increased hospital admissions from both sugarcane straw burning and urban air pollution in São Paulo State $[17,18,61,62]$. In general, the impacts we report here should be viewed alongside other potential ancillary benefits or disbenefits of the different fuels.

\section{Conclusions}

Our findings suggest that, contrary to what is often claimed, a transport fuel policy in São Paulo State that prioritizes gasoline over ethanol could result in lower $\mathrm{PM}_{2.5}$ and ozone and less premature mortality from air pollution. Specifically, the expansion of ethanol production and use, in line with government projections, could lead to tens of thousands fewer life-years lived per year compared to a fossil fuel scenario. However, we stress that this is not an argument in favor of fossil fuels, but instead demonstrates the need to continue to limit emissions in the transport sector, with strategies likely to include a combination of improved vehicle technologies, economic incentives and modal shifts towards mass transit and active travel.

Supplementary Materials: The following are available online at www.mdpi.com/1660-4601/13/7/695/s1, Section S1: Area Harvested and Burnt, Section S2: Transport Energy Demand, Section S3: Vehicle Emission Factors, Section S4: Vehicle Emissions over Time, Section S5: Development of life Tables, Section S6: Maps of Total $\mathrm{PM}_{2.5}$ and Ozone in Each Scenario, Section S7: Differences in Air Pollution in Select Groups of Municipalities, Section S8: Health Impacts by Cause, Section S9: Impacts using coefficients for all-cause mortality $\left(\mathrm{PM}_{2.5}\right)$.

Acknowledgments: We thank the São Paulo Research Foundation (FAPESP_projects 2008/56252-0 and 2013/18884-2), the Coordination for the Improvement of Higher Education Personnel, the Carlos Chagas Filho Foundation for Research Support of the State of Rio de Janeiro (CAPES/FAPERJ partnership-project E-26/201.221/2015), and the Colt Foundation (UK) for financial support.

Author Contributions: N. S., D. F., K. L. and P. W. conceived of and designed the study; C. A. modeled future sugarcane expansion and harvesting practices; B. R. conducted the processing of sugarcane reference data; D. F. and M. A. conducted the air quality modeling with support from K. L. and S. F.; D. F., M. A., K. L. and S. F. interpreted the air quality results; N. S. conducted the health impact modeling; N. S. and P. W. interpreted the health impact results; N. S., D. F. and M. A. wrote the paper with suggestions from all authors.

Conflicts of Interest: The authors declare no conflict of interest. The funding sponsors had no role in the design of the study; in the collection, analyses, or interpretation of data; in the writing of the manuscript, and in the decision to publish the results. 


\section{Abbreviations}

The following abbreviations are used in this manuscript:

$\begin{array}{ll}\text { CCATT-BRAMS } & \begin{array}{l}\text { Coupled Chemistry Aerosol and Tracer Transport model to the Brazilian } \\ \text { developments on the Regional Atmospheric Modeling System }\end{array} \\ \text { CI } & \text { Confidence interval } \\ \text { EE } & \text { Ethanol Expansion (scenario) } \\ \text { FF } & \text { Fossil Fuel (scenario) } \\ \text { MW } & \text { Megawatt } \\ \text { NOx } & \text { oxides of nitrogen } \\ \text { PM }_{2.5} & \text { Fine particulate matter } \\ \text { VOC } & \text { Volatile organic compound } \\ \text { WHO } & \text { World Health Organization }\end{array}$

\section{References}

1. Renewable Fuels Association. World Fuel Ethanol Production. Available online: http://www.ethanolrfa. org/resources/industry/statistics/-1454098996479-8715d404-e546 (accessed on 11 February 2016).

2. International Energy Agency. World Energy Outlook 2014; IEA/OECD: Paris, France, 2014.

3. REN21. Renewables Global Futures Report; REN21: Paris, France, 2014.

4. Renewable Fuels Association. Ethanol Facts: Environment. Available online: http://www.ethanolrfa.org/ pages/ethanol-facts-environment (accessed on 7 January 2014).

5. UNICA and Apex Brasil. Sugarcane Benefits: Improved Public Health. Available online: http://sugarcane. org/sugarcane-benefits/improved-public-health (accessed on 7 January 2014).

6. Anderson, L.G. Effects of biodiesel fuels use on vehicle emissions. J. Sustain. Energy Environ. 2012, 3, 35-47.

7. Niven, R. Ethanol in gasoline: Environmental impacts and sustainability review article. Renew. Sustain. Energy Rev. 2005, 9, 535-555. [CrossRef]

8. Tessum, C.; Marshall, J.D.; Hill, J. Tank to Wheel Emissions of Ethanol and Biodiesel Powered Vehicles as Compared to Petroleum Alternatives; Center for Transportation Studies, University of Minnesota: Minneapolis, MN, USA, 2010; p. 10.

9. Scovronick, N.; Wilkinson, P. Health impacts of liquid biofuel production and use: A review. Glob. Environ. Chang. 2014, 24, 155-164. [CrossRef]

10. Wallington, T.; Anderson, J.; Kurtz, E.; Tennison, P. Biofuels, vehicle emissions and urban air quality. Faraday Discuss. 2016. [CrossRef] [PubMed]

11. Goldemberg, J.; Coelho, S.; Guardabassi, P. The sustainability of ethanol production from sugarcane. Energy Policy 2008, 36, 2086-2097. [CrossRef]

12. ANFAVEA. Anuário da Indústria Automobilística Brasileira 2014; ANFAVEA: São Paulo, Brazil, 2014.

13. Empresa de Pesquisa Energética. Balanço Energético Nacional 2014; EPE: Rio de Janeiro, Brazil, 2014.

14. UNICA. How Important Is Sugarcane to Meeting Brazil's Energy Needs? Available online: http://www. unica.com.br/faq/ (accessed on 12 February 2016).

15. UNICA. Unicadata. Available online: http://www.unicadata.com.br/historico-de-producao-e-moagem. php?idMn=31\&tipoHistorico=2 (accessed on 11 February 2016).

16. Arbex, M.; Bohm, G.; Saldiva, P.; Conceiçao, G.; Pope, A.; Braga, A. Assessment of the effects of sugar cane plantation burning on daily counts of inhalation therapy. J. Air Waste Manag. Assoc. 2000, 50, 1745-1749. [CrossRef] [PubMed]

17. Arbex, M.; Martins, L.; de Oliveira, R.; Pereira, L.; Arbex, F.; Cancado, J.; Saldiva, P.; Braga, A. Air pollution from biomass burning and asthma hospital admissions in a sugar cane plantation area in brazil. J. Epidemiol. Community Health 2007, 61, 395-400. [CrossRef] [PubMed]

18. Cançado, J.; Saldiva, P.; Pereira, L.; Lara, L.; Artaxo, P.; Martinelli, L.; Arbex, M.; Zanobetti, A.; Braga, A. The impact of sugar cane-burning emissions on the respiratory system of children and the elderly. Environ. Health Perspect. 2006, 114, 725-729. [CrossRef] [PubMed]

19. Goto, D.M.; Lanca, M.; Obuti, C.A.; Galvao Barbosa, C.M.; Nascimento Saldiva, P.H.; Trevisan Zanetta, D.M.; Lorenzi-Filho, G.; de Paula Santos, U.; Nakagawa, N.K. Effects of biomass burning on nasal mucociliary clearance and mucus properties after sugarcane harvesting. Environ. Res. 2011, 111, 664-669. [CrossRef] [PubMed]

20. World Health Organizaton. Ambient (Outdoor) Air Pollution in Cities Database 2014. Available online: http://www.who.int/phe/health_topics/outdoorair/databases/cities/en/ (accessed on 11 February 2016). 
21. World Health Organizaton. Who Air Quality Guidelines for Particulate Matter, Ozone, Nitrogen Dioxide and Sulfur Dioxide: Global Update 2005; WHO: Geneva, Switzerland, 2006.

22. Empresa de Pesquisa Energética. Plano Nacional de Energia 2030; MME/EPE: Rio de Janeiro, Brazil, 2007.

23. França, D.; Longo, K.; Neto, T.; Santos, J.; Freitas, S.; Rudorff, B.; Cortez, E.; Anselmo, E.; Carvalho, J. Pre-harvest sugarcane burning: Determination of emission factors through laboratory measurements. Atmosphere 2012, 3, 164-180. [CrossRef]

24. Yokelson, R.J.; Christian, T.J.; Karl, T.; Guenther, A. The tropical forest and fire emissions experiment: Laboratory fire measurements and synthesis of campaign data. Atmos. Chem. Phys. 2008, 8, 3509-3527. [CrossRef]

25. Alonso, M. Previsão de Tempo Químico Para a America do Sul: Impacto das Emissões Urbanas nas Escalas Local e Regional; INPE: São Jose dos Campos, Brazil, 2011.

26. MCT. Segundo Inventário Brasileiro de Emissões Antrópicas de Gases do Efeito Estufa; Ministério da Ciência e Tecnologia: Brasília, Brazil, 2010.

27. ANFAVEA. Brazilian Automotive Industry Yearbook; Brazilian Automotive Industry Association: São Paulo, Brazil, 2010.

28. ANFAVEA. Brazilian Automotive Industry Yearbook; ANFAVEA: São Paulo, Brazil, 2013.

29. CETESB. Emissões Veiculares no Estado de São Paulo 2011; CETESB: São Paulo, Brazil, 2012.

30. U.S. Environmental Protection Agency. Technical Support Document: Preparation of Emissions Inventories for the Version 4.1, 2005-Based Platform. Available online: https:/ /www.epa.gov/sites/production/files/ 2015-11/documents/2005v4.1_main.pdf (accessed on 28 June 2016).

31. De Gouvello, C. Estudo de Baixo Carbono Para o Brasil; World Bank: Washington, DC, USA, 2010.

32. Alonso, M.F.; Longo, K.M.; Freitas, S.R.; Mello da Fonseca, R.; Marécal, V.; Pirre, M.; Klenner, L.G. An urban emissions inventory for south america and its application in numerical modeling of atmospheric chemical composition at local and regional scales. Atmos. Environ. 2010, 44, 5072-5083. [CrossRef]

33. Freitas, S.; Longo, K.; Alonso, M.; Pirre, M.; Marecal, V.; Grell, G.; Stockler, R.; Mello, R.; Sánchez Gácita, M. Prep-chem-src-1.0: A preprocessor of trace gas and aerosol emission fields for regional and global atmospheric chemistry models. Geosci. Model. Dev. 2011, 4, 419-433. [CrossRef]

34. Longo, K.; Freitas, S.; Pirre, M.; Marécal, V.; Rodrigues, L.; Panetta, J.; Alonso, M.; Rosário, N.; Moreira, D.; Gácita, M.; et al. The chemistry catt-brams model (ccatt-brams 4.5): A regional atmospheric model system for integrated air quality and weather forecasting and research. Geosci. Model. Dev. 2013, 6, 1389-1405. [CrossRef]

35. Guenther, A.; Karl, T.; Harley, P.; Wiedinmyer, C.; Palmer, P.; Geron, C. Estimates of global terrestrial isoprene emissions using megan (model of emissions of gases and aerosols from nature). Atmos. Chem. Phys. 2006, 6, 3181-3210. [CrossRef]

36. Freitas, S.; Longo, K.; Silva Dias, M.; Chatfield, R.; Silva Dias, P.; Artaxo, P.; Andreae, M.; Grell, G.; Rodrigues, L.; Fazenda, A.; et al. The coupled aerosol and tracer transport model to the brazilian developments on the regional atmospheric modeling system (catt-brams)-Part 1: Model description and evaluation. Atmosp. Chem. Phys. Discuss. 2009, 9, 2843-2861. [CrossRef]

37. Miller, B.; Hurley, J. Comparing Estimated Risks for Air Pollution with Risks for Other Health Effects; Institute of Occupational Medicine: Edinburgh, UK, 2006.

38. Miller, B. Iomlifet: A Spreadsheet System for Life Table Calculation for Health Impact Assessment. Available online: http://www.iom-world.org/research/research-expertise/statistical-services/iomlifet/ (accessed on 15 February 2016).

39. Ministério da Saúde. Mortalidade-São Paulo (2011). Available online: http://tabnet.datasus.gov.br/cgi/ deftohtm.exe?sim/cnv/obt10SP.def (accessed on 21 February 2014).

40. Instituto Brasileiro de Geografia e Estatística. Censo demográfico 2010: Tabela 1.12-População Residente, por Sexo e Grupos de Idade, Segundo as Grandes Regiões e as Unidades da Federação-2010. Available online: http://www.ibge.gov.br/home/estatistica/populacao/censo2010/tabelas_pdf/Brasil_tab_1_12.pdf (accessed on 21 February 2014).

41. Instituto Brasileiro de Geografia e Estatística. Censo demográfico 2010: Tabela 1.1.1—População Residente, por Situação do Domicílio e Sexo, Segundo os Grupos de Idade-Brasil-2010. Available online: http://www.ibge.gov.br/home/estatistica/populacao/censo2010/caracteristicas_da_populacao/ caracteristicas_da_populacao_tab_brasil_zip_ods.shtm (accessed on 21 February 2014). 
42. Brook, R.D.; Rajagopalan, S.; Pope, C.A.; Brook, J.R.; Bhatnagar, A.; Diez-Roux, A.V.; Holguin, F.; Hong, Y.; Luepker, R.V.; Mittleman, M.A.; et al. Particulate matter air pollution and cardiovascular disease an update to the scientific statement from the american heart association. Circulation 2010, 121, 2331-2378. [CrossRef] [PubMed]

43. WHO. Review of Evidence on Health Aspects of Air Pollution-Revihaap Project; World Health Organization Regional Office for Europe: Copenhagen, Denmark, 2013.

44. Forestiere, F.; Kan, H.; Cohen, A. Updated exposure-response functions available for estimating mortality impacts. In Who Expert Meeting: Methods and Tools for Assessing the Health Risks of Air Pollution at Local, naTional and International Level; World Health Organization Regional Office for Europe: Copenhagen, Denmark, 2014.

45. Hoek, G.; Krishnan, R.; Beleen, R.; Peters, A.; Ostro, B.; Brunekreef, B.; Kaufman, J. Long-term air pollution exposure and cardio-Respiratory mortality: A review. Environ. Health 2013, 12, 43. [CrossRef] [PubMed]

46. Hamra, G.B.; Guha, N.; Cohen, A.; Laden, F.; Raaschou-Nielsen, O.; Samet, J.M.; Vineis, P.; Forastiere, F.; Saldiva, P.; Yorifuji, T.; et al. Outdoor particulate matter exposure and lung cancer: A systematic review and meta-analysis. Environ. Health Perspect. 2014, 122, 906-911. [CrossRef] [PubMed]

47. Jerrett, M.; Burnett, R.T.; Pope, C.A., III; Ito, K.; Thurston, G.; Krewski, D.; Shi, Y.; Calle, E.; Thun, M. Long-term ozone exposure and mortality. N. Engl. J. Med. 2009, 360, 1085-1095. [CrossRef] [PubMed]

48. CETESB. Emissões Veiculares no Estado de São Paulo 2013; CETESB: São Paulo, Brazil, 2014.

49. De Miranda, R.M.; de Fatima Andrade, M.; Fornaro, A.; Astolfo, R.; de Andre, P.A.; Saldiva, P. Urban air pollution: A representative survey of $\mathrm{PM}_{2.5}$ mass concentrations in six brazilian cities. Air Qual. Atmos. Health 2012, 5, 63-77. [CrossRef] [PubMed]

50. Hill, J.; Polasky, S.; Nelson, E.; Tilman, D.; Huo, H.; Ludwig, L.; Neumann, J.; Zheng, H.; Bonta, D. Climate change and health costs of air emissions from biofuels and gasoline. Proc. Natl. Acad. Sci. USA 2009, 106, 2077-2082. [CrossRef] [PubMed]

51. Jacobson, M. Effects of ethanol (e85) versus gasoline vehicles on cancer and mortality in the united states. Environ. Sci. Technol. 2007, 41, 4150-4157. [CrossRef] [PubMed]

52. Miraglia, S.G.E.K. Health, environmental, and economic costs from the use of a stabilized diesel/ethanol mixture in the city of são paulo, brazil. Cad. Saude Publica 2007, 23, S559-S569. [CrossRef] [PubMed]

53. Salvo, A.; Geiger, F.M. Reduction in local ozone levels in urban são paulo due to a shift from ethanol to gasoline use. Nat. Geosci. 2014, 7, 450-458. [CrossRef]

54. Angelo, C. Growth of ethanol fuel stalls in brazil. Nature 2012, 491, 646-647. [CrossRef] [PubMed]

55. Empresa de Pesquisa Energética. Demanda de Energia 2050; MME/EPE: Rio de Janeiro, Brazil, 2016.

56. Anenberg, S.; Horowitz, L.; Tong, D.; West, J. An estimate of the global burden of anthropogenic ozone and fine particulate matter on premature human mortality using atmospheric modeling. Environ. Health Perspect. 2010, 118, 1189-1195. [CrossRef] [PubMed]

57. Krewski, D.; Jerrett, M.; Burnett, R.T.; Ma, R.; Hughes, E.; Shi, Y.; Turner, M.C.; Pope, C.A., III; Thurston, G.; Calle, E.E.; et al. Extended Follow-up and Spatial Analysis of the American Cancer Society Study Linking Particulate Air Pollution and Mortality; Health Effects Institute: Boston, MA, USA, 2009.

58. CETESB. Emissões Veiculares no Estado de São Paulo 2014; CETESB: São Paulo, Brazil, 2015.

59. UNICA and Apex Brasil. Sugarcane Best Cultivation Practices. Available online: http://sugarcane.org/ sustainability/best-practices (accessed on 8 January 2014).

60. Zilberman, D.; Hochman, G.; Rajagopal, D.; Sexton, S.; Timilsina, G. The impact of biofuels on commodity food prices: Assessment of findings. Am. J. Agric. Econ. 2013, 95, 275-281. [CrossRef]

61. Arbex, M.; Saldiva, P.; Pereira, L.; Braga, A. Impact of outdoor biomass air pollution on hypertension hospital admissions. J. Epidemiol. Community Health 2010, 64, 573-579. [CrossRef] [PubMed]

62. Braga, A.L.; Saldiva, P.H.; Pereira, L.A.; Menezes, J.J.; Conceição, G.M.; Lin, C.A.; Zanobetti, A.; Schwartz, J.; Dockery, D.W. Health effects of air pollution exposure on children and adolescents in São Paulo, Brazil. Pediatr. Pulmonol. 2001, 31, 106-113. [CrossRef]

(C) 2016 by the authors; licensee MDPI, Basel, Switzerland. This article is an open access article distributed under the terms and conditions of the Creative Commons Attribution (CC-BY) license (http://creativecommons.org/licenses/by/4.0/). 